\title{
Influence of Applied Frequency on Microstructural and Electrochemical Characteristics of Ceramic Coating Produced on Al-Mg Alloy by Pulsed Plasma Electrolytic Oxidation
}

\author{
J.H. LEE ${ }^{a}$, S.J. $\operatorname{LEE}^{b}$ AND S.J. KIM ${ }^{c, *}$ \\ ${ }^{a}$ Korea Testing \& Research Institute, Key Industry Division, Jongga-ro 15, Ulsan, 44412, Korea \\ ${ }^{b}$ Kunsan National University, Department of Power System Engineering, Daehak-ro 558, Kunsan-si, Jeonbuk, Korea \\ ${ }^{c}$ Division of Marine Engineering, Mokpo National Maritime University, \\ Haeyangdaehak-Ro 91 Mokpo-si, Jeonnam, 530-729 Korea
}

\begin{abstract}
Plasma electrolytic oxidation (PEO) coating is gaining attention as a promising surface treatment technique for lightweight metals and alloys such as $\mathrm{Al}, \mathrm{Mg}$ and $\mathrm{Ti}$. The coating involves complex interactions among various process parameters including substrate composition, current modes and electrolyte composition. In this study, ceramic coating was produced in silicate based alkaline solution on Al-Mg alloy by pulsed PEO with different applied frequencies $(100,500,1000,2000 \mathrm{~Hz})$. The resultant coating was characterized using FE-SEM, EDS and HR-XRD. The electrochemical characteristics of the PEO coating were also investigated in seawater solution. It was found that changing frequency in the PEO process had a prominent effect on both surface and crosssectional morphology of the coating. The electrochemical studies indicated that the pulsed PEO have improved the corrosion resistance of the $\mathrm{Al}-\mathrm{Mg}$ substrate. In particular, the applied frequency of $100 \mathrm{~Hz}$ has produced one order of magnitude lower corrosion current density than that of the Al-Mg substrate.
\end{abstract}

DOI: 10.12693/APhysPolA.129.753

PACS/topics: 81.16.Pr

\section{Introduction}

With the increasing demand on lightweight materials, $\mathrm{Al}$ alloys have received great attention for alternative material to replace conventional materials such as steel, since they have excellent strength to weigh ratio, thermal conductivity and electrical conductivity despite of their low density. However, because of their relatively low hardness, Al alloys have poor wear resistance compared with other alloys. Such poor surface properties constitute an obstacle to spreading of $\mathrm{Al}$ alloys for lightweight material, and therefore surface modification of the alloys are essential in practical applications. Plasma electrolytic oxidation (PEO) is a novel surface treatment technique for valve metals such as $\mathrm{Al}, \mathrm{Mg}$ and $\mathrm{Ti}$ which converts the metal surface into ceramic oxide layer using microdischarge on surface. It is a similar process to anodizing but it is carried out at a higher voltage in dilute alkaline solutions. The hard ceramic coating layer produced by PEO possesses excellent corrosion, wear and thermal resistance, thus having a commercial appeal. There are increasingly many studies of PEO technology being undertaken in various countries across the world. These studies focus on surface enhancement by varying electrolyte composition or electrical parameters or explore the technical feasibility for commercialization by evaluating the

*corresponding author; e-mail: ksj@mmu.ac.kr coating layer in terms of corrosion, wear and thermal resistance. Particularly, PEO coating technology with a pulsed current provides easy control of coating properties by adjusting duty ratio and frequency of pulse. The pulsed PEO coating produces relatively uniform and compact coating layer compared to normal current mode. Comprehensive work was carried out by A.L. Yerokhin et al. and R.O. Hussein et al. related to the influence of electrical parameters on coating characteristics in pulsed $\mathrm{PEO}$ coating process for $\mathrm{Al}$ and $\mathrm{Al}$ alloys [1-3]. However, the materials in their investigations were limited to 1000 or 6000 series $\mathrm{Al}$ alloy, and only a few studies have dealt with Al-Mg alloy. In this paper, PEO coating was fabricated on $\mathrm{Al}-\mathrm{Mg}$ alloy in a pulsed current regime at different current frequencies. Various characterizations of the coating were carried out including surface and cross-sectional observation, elemental analysis, identification of crystalline structure and measurement of thickness and roughness along with electrochemical evaluation. The influence of applied frequency on coating layer was investigated.

\section{Experimental method}

The Al-Mg alloy (Si: 0.40, Fe: 0.15, Cu: 0.18, Mn: 0.18, Mg: 6.42, Cr: 0.12, Zn: 0.12, Ti: 0.01, Al: bal. wt.\%) was used in this study as a substrate for PEO coating process. A rectangular sample with dimension of $20 \times 20 \times 5 \mathrm{~mm}^{3}$ was mounted with epoxy resin to expose only the desired surface area of $4 \mathrm{~cm}^{2}$ for PEO process, with conducting wire threaded to the opposite side. The sample 
was polished with emery polishing paper up to 1000 grit, and then rinsed with acetone and deionized water, followed by hot air drying. The positive terminal of DC power supply was connected to the sample serving as anode and the negative terminal was connected to STS304 plate $\left(150 \times 300 \mathrm{~mm}^{2}\right)$ acting as cathode. The unipolar DC pulsed current of $0.1 \mathrm{~A} / \mathrm{cm}^{2}$ was applied to two electrodes immersed in an electrolyte solution at different frequencies $(100,500,1000$ and $2000 \mathrm{~Hz})$ for 30 minutes while keeping the duty cycle at $20 \%$. The micro-discharge phenomenon on surface during PEO coating process was recorded with digital camera. The process was carried out in dilute alkaline solution $\left(\mathrm{KOH}: 2 \mathrm{~g} / \mathrm{L}+\mathrm{Na}_{2} \mathrm{SiO}_{3}\right.$ : $2 \mathrm{~g} / \mathrm{L})$ temperature of which was maintained at approximately $20^{\circ} \mathrm{C}$ by circulation and chilling of the electrolyte. After the coating process, the surface and cross-section of the PEO coating was observed with FE-SEM. EDS analysis was carried out to reveal elemental composition of the coating, and the crystalline phase was identified by HR-XRD. The thickness of the coating was measured with eddy-current thickness gauge, and the average of 20 readings was considered to be the thickness of the coating. The roughness of the coating surface was measured by 3D optical microscope with cut-off length of $0.8 \mu \mathrm{m}$, and the roughness value was averaged over 10 measurements. Potentiodynamic polarization experiment for non-processed substrate and PEO coatings was carried out to investigate the electrochemical characteristics of the coating in seawater solution. The polarization experiment was carried out in a three-electrode cell, the working electrode was the PEO-processed sample with an exposed area of $1 \mathrm{~cm}^{2}$; Pt mesh was used as counter electrode; $\mathrm{Ag} / \mathrm{AgCl}$ was used as reference electrode. The polarization was conducted from open circuit potential (OCP) to the anodic and cathodic directions $(\mathrm{OCP} \pm 0.25 \mathrm{~V})$ with a scanning rate of $1 \mathrm{~V} / \mathrm{min}$. The obtained polarization curves were analyzed with Tafel extrapolation method to determine the corrosion potential and corrosion current density.

\section{Results and discussion}

Figures $1 \mathrm{a}$ and $\mathrm{b}$ represent the voltage-time response and the corresponding micro-discharge evolution with time during PEO coating process with different applied frequencies, respectively. Typical voltage-time response during PEO coating process constitutes a rapid increase of voltage at very early stage where the oxide layer is formed by oxidation reaction, followed by a moderate increase of voltage at certain range [4]. In this voltage range (referred to breakdown voltage), dielectric breakdown occurs with visible micro-discharge on surface, accompanied by destruction of the previously formed oxide layer and growth of ceramic layer. In this study, from observation of the micro-discharge event, the breakdown voltages for all PEO coatings were determined to be approximately $460 \mathrm{~V}$, showing a negligible dependence on the applied frequency. This is in accordance with the previous finding that the duty cycle during unipolar pulsed PEO

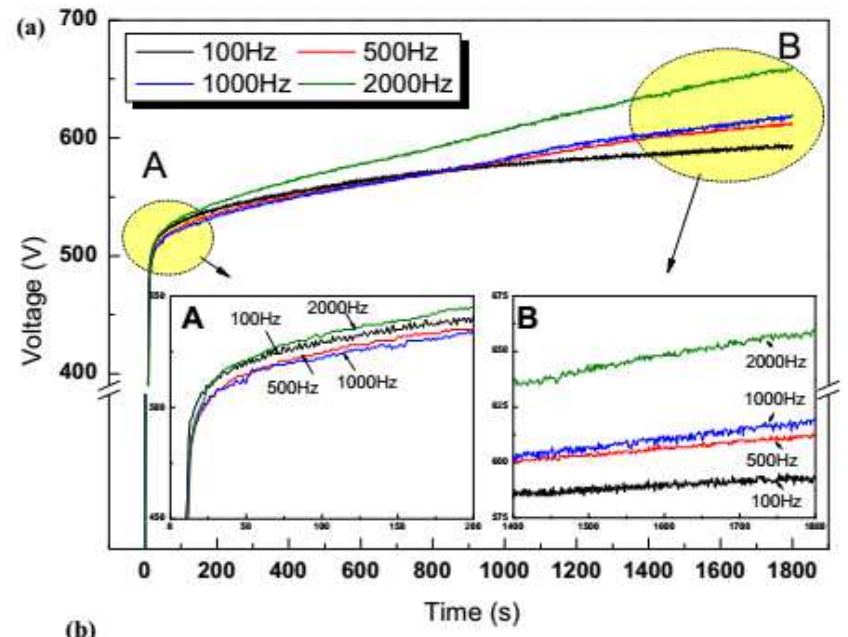

(b)



Fig. 1. Voltage-time response (a) and the corresponding micro-discharge evolution vs time (b) for PEO coating carried out at different frequencies.

coating is the prominent influencing factor on breakdown voltage rather than the frequency [5]. However, voltagetime behavior after the breakdown voltage was distinctive for different applied frequencies. It was observed that the increase of voltage was retarded for the applied frequency of $100 \mathrm{~Hz}$, which is referred as the critical voltage. In the case of applied frequency of 500, 1000 and $2000 \mathrm{~Hz}$, on the other hand, the voltage continued to increase gradually throughout the PEO coating process without the presence of critical voltage, which implies development of micro-discharge into localized arc discharge. At final stage, the applied frequency of $2000 \mathrm{~Hz}$ has generated the highest voltage of $660 \mathrm{~V}$, while the frequency of $100 \mathrm{~Hz}$ showed the lowest voltage of $594 \mathrm{~V}$ among tested PEO processes. In this study, the overall micro-discharge evolution with time for PEO coating process involved three stages: (i) initial stage at breakdown voltage: uniform distribution of micro-discharges over surface (color: white); (ii) intermediate stage: decreased density but increased size of micro-discharges (color: yellow); (iii) final stage: further decreased density and transformation of the micro-discharge into arc (color: orange). The intensity of the micro-discharge at dielectric breakdown voltage could be distinguished very well between the applied 
frequencies. The frequency of $100 \mathrm{~Hz}$ can be characterized by relatively high intensity of micro-discharge during overall PEO process, compared to the other frequencies, and this was particularly pronounced at breakdown voltage.

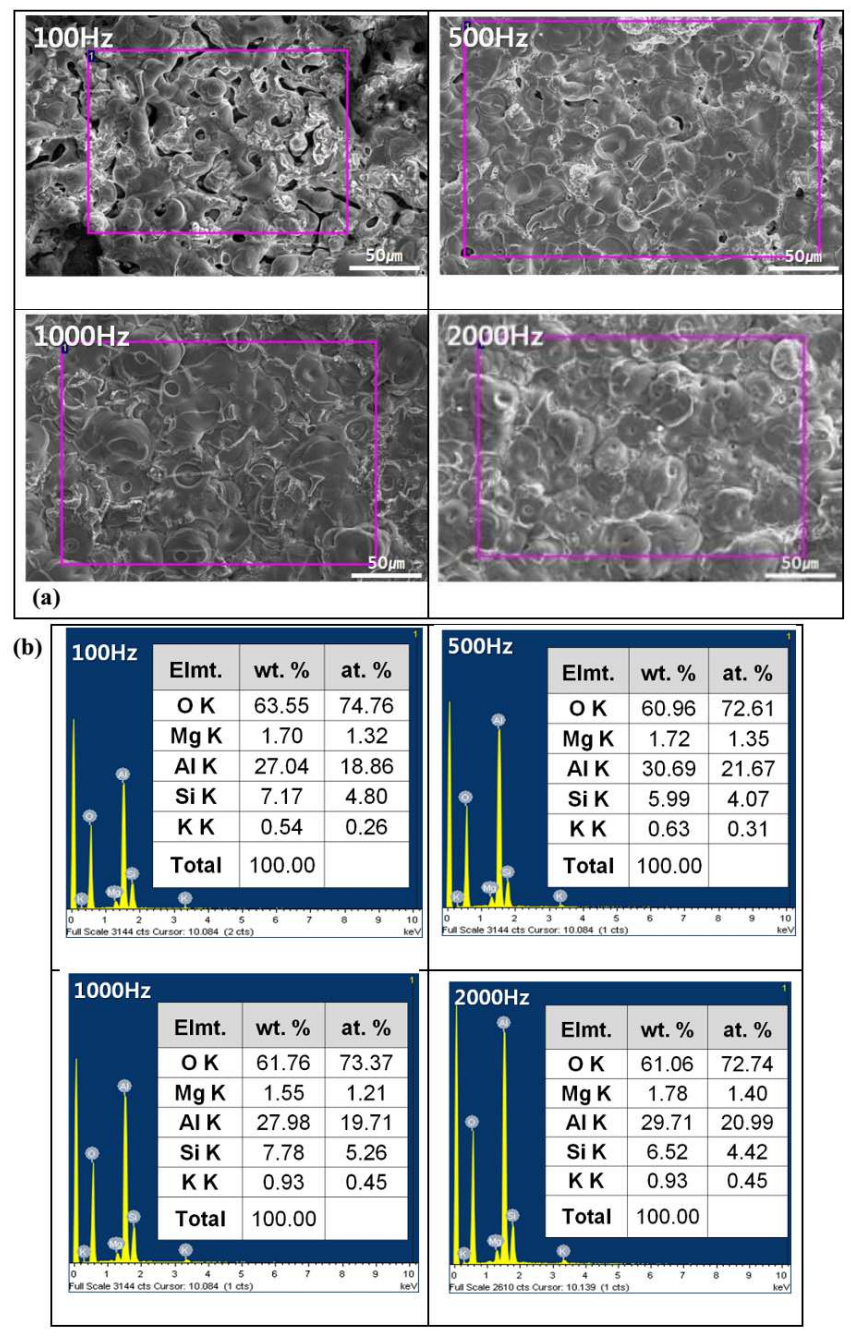

Fig. 2. FE-SEM images (a) and corresponding EDS spectra (b) for surface of PEO coatings produced at different frequencies.

Figure 2 presents FE-SEM images for surface of PEO coatings produced at different frequencies and the corresponding EDS spectra with the result of elemental analysis. It was noticed that the surface produced at frequency of $100 \mathrm{~Hz}$ had presented a relatively porous structure, while $500 \mathrm{~Hz}$ had generated a "volcano-like structure", also referred as "crater", over the surface and this might somewhat reduce the porosity, but some pores were still observed. At the applied frequency of $1000 \mathrm{~Hz}$ and $2000 \mathrm{~Hz}$, the crater structure was dominant over the entire surface with significantly reduced porosity. The appearance of craters is a typical surface feature of PEO coating, which is produced when the molten substrate material by high temperature plasma is erupted from coating-substrate interface and rapidly solidifies by the electrolyte at relatively low temperature [6]. The presence of a central pore on the crater indicated the discharging channel through which molten $\mathrm{Al}$ substrate has erupted. It was also observed that the number of craters showed an increasing tendency with the increasing applied frequency, and this is attributed to the short-lived plasma discharge due to relatively higher frequencies. The result of elemental analysis by EDS has revealed the elemental composition for the surface of PEO coating layer to contain $\mathrm{Al}, \mathrm{Mg}, \mathrm{Si}, \mathrm{O}$ with trace amounts of $\mathrm{K}$. It is considered that the $\mathrm{Al}$ and $\mathrm{Mg}$ were derived from the substrate, while both $\mathrm{K}$ and $\mathrm{Si}$ were electrolyte constituents. This confirms that the ceramic oxide layer existed mostly in the form of Al-based oxides or Si-based oxides. It was also revealed that a compositional difference was not pronounced between PEO coatings produced with different frequencies. This indicates that electrolyte composition or additives may exert more noticeable influences on composition of PEO coating, rather than the electrical parameters.

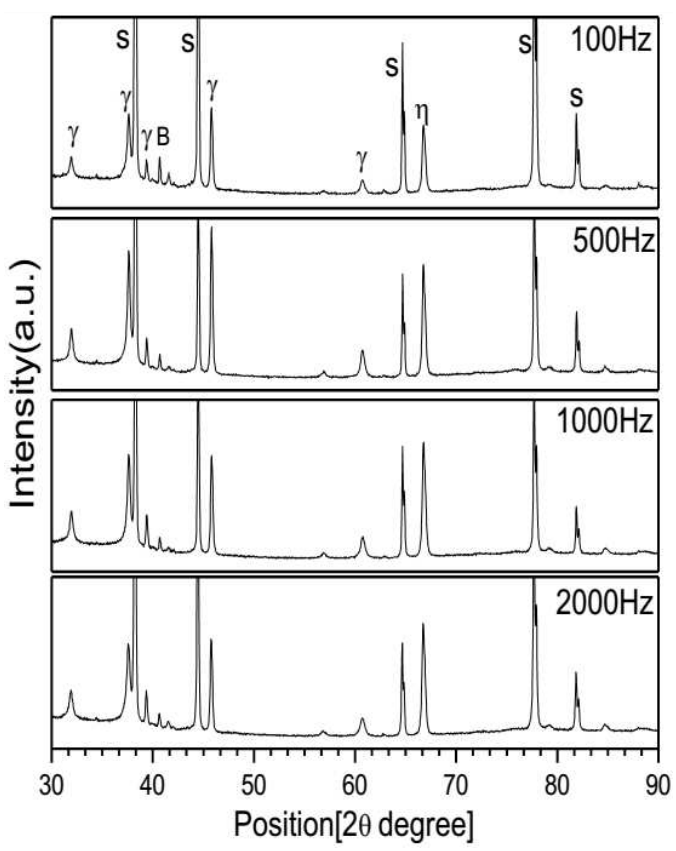

Fig. 3. X-ray diffraction pattern for PEO coating produced at different frequencies (s: substrate, $\gamma$ : $\gamma$ alumina, $\eta$ : $\eta$-alumina, B: bayerite).

Figure 3 displays the X-ray diffraction patters of $\mathrm{PEO}$ coatings produced at different frequencies. All PEO coating layers, irrespective of applied frequency, had $\gamma$ alumina $\left(\gamma-\mathrm{Al}_{2} \mathrm{O}_{3}\right)$ and $\eta$-alumina $\left(\eta-\mathrm{Al}_{2} \mathrm{O}_{3}\right)$ peaks along with $\mathrm{Al}$ diffraction peaks. This suggests that the produced PEO coatings had $\gamma$-alumina as the main crystalline phase. This agrees with the previous report that the $\mathrm{PEO}$ coating of Al alloy with high amount of Mg produces $\gamma$-alumina as a dominant crystalline phase [4-5]. In this study, it appears that the the produced aluminas were synthesized by two different processes. Generally, 
$\gamma$-alumina is one of transition aluminas with metastable phase, that are obtained by the thermal decomposition of $\mathrm{Al}$ hydroxides $\left(\mathrm{Al}(\mathrm{OH})_{3}\right)$. It is known to be formed under sintering in the temperature range of $450-750{ }^{\circ} \mathrm{C}$ [7]. From the result of XRD analysis, the $\gamma$-alumina is assumed to be derived from boehmite $(\gamma-\mathrm{AlO}(\mathrm{OH}))$, which is an $\mathrm{Al}$ oxide hydroxide and is later transformed into $\gamma$-alumina due to hydrothermal reaction driven by PEO process. On the other hand, the $\eta$-alumina is considered to be developed from bayerite $\left(\alpha-\mathrm{Al}(\mathrm{OH})_{3}\right)$, which is confirmed by the presence of weak bayerite peak in the XRD pattern. Moreover, higher peak intensities of $\eta$-alumina were observed with the increasing applied frequency, and this is considered to be associated with insufficient hydrothermal reaction due to short-lived micro-discharge at relatively higher frequencies. For a given substrate composition, the formation of Al-Mg spinel $\left(\mathrm{MgAl}_{2} \mathrm{O}_{4}\right)$ was expected due to high-temperature plasma reaction, however the corresponding peak was not detected in this study. Furthermore, mullite $\left(3 \mathrm{Al}_{2} \mathrm{O}_{3} \cdot 2 \mathrm{SiO}_{2}\right)$ peak was not detected, which is typically observed in PEO process of $\mathrm{Al}$ alloys with silicate based electrolyte. This is believed to be due to relatively low concentration of $\mathrm{Na}_{2} \mathrm{SiO}_{3}$ in the electrolyte.

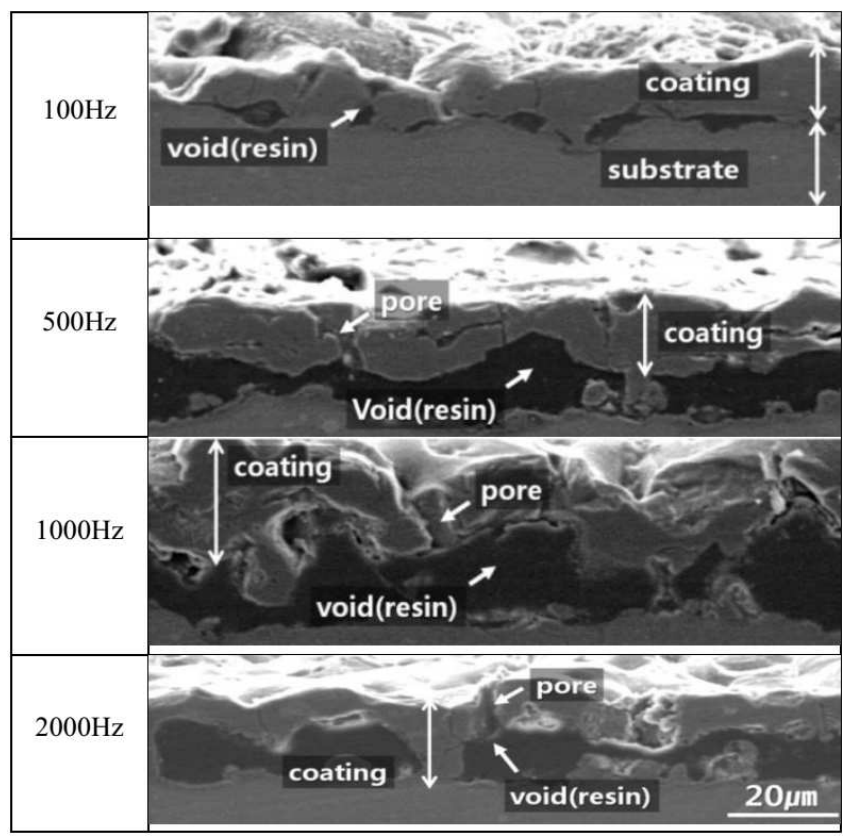

Fig. 4. Cross-sectional view of PEO coatings produced at different frequencies.

Figure 4 exhibits the cross-sectional SEM observation for the PEO coatings produced at different frequencies. It is evident that different cross-sectional morphology was produced at different applied frequencies. The dark area in the images indicates a hallow section filled with epoxy resin during the specimen preparation for SEM observation, and it represents the cross-sectional pore shape in the coating. It is observed that the PEO coatings had a wavy irregular structure developed along substratecoating interface, and this could possibly be due to selective dissolution of substrate or intermetallic compounds at the grain boundary during the PEO process [8]. Furthermore, it was noted that the coating thickness had increased with the increasing frequencies. This result conflicts with the result from the earlier work by other researcher, in which at low duty cycle of $20 \%$ the increasing frequency tends to decrease coating thickness, while at high duty cycle the effect of frequency becomes negligible [1]. This could be attributed to the difference in experimental conditions such as the substrate and the electrolyte compositions [9]. It is clearly seen from the SEM images that the PEO coating produced at frequency of $100 \mathrm{~Hz}$ presents a relatively dense microstructure with low porosity, compared with those produced at higher frequencies. On the whole, it appears that the crosssection of PEO coatings had more porosity and throughthickness pores with the increasing frequency. The presence of such porosity in the coating greatly influences the corrosion resistance of PEO coating system, providing a path for permeation of corrosive solution or a reservoir for the solution [10].

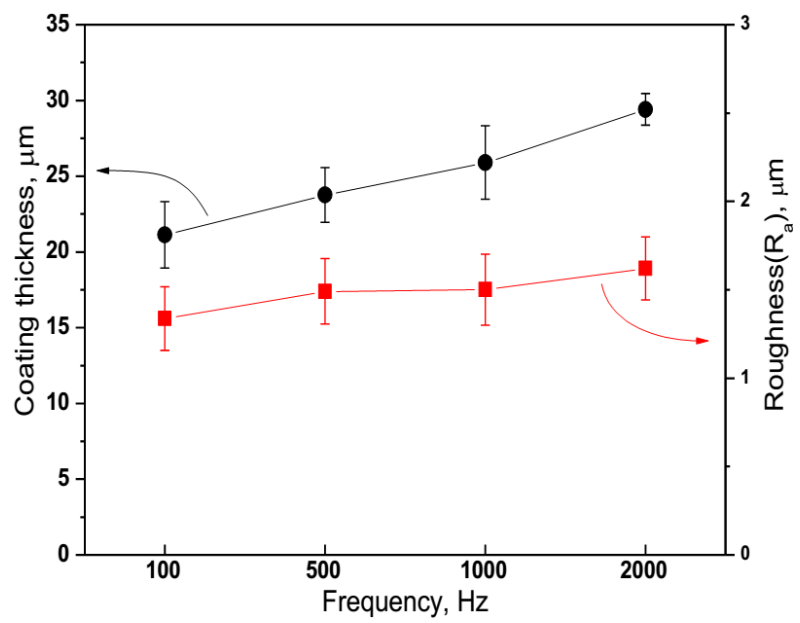

Fig. 5. Thickness and roughness of PEO coatings produced at different frequencies.

Figure 5 demonstrates the variation of thickness and surface roughness of PEO coatings produced at different applied frequencies. It is clear that the coating thickness shows an increasing tendency with the increase of the applied frequency. The PEO coating with applied frequency of $100 \mathrm{~Hz}$ had thickness of approximately $21 \mu \mathrm{m}$, while a thickness of $29 \mu \mathrm{m}$ was obtained at $2000 \mathrm{~Hz}$, showing 1.3 times difference between values at maximum and minimum frequency. The surface roughness for coatings processed at $100 \mathrm{~Hz}$ and $2000 \mathrm{~Hz}$ were determined to be $1.3 \mu \mathrm{m}$ and $1.6 \mu \mathrm{m}$, respectively, and this could indicate an increasing tendency of surface roughness but at the same time seems to be a minor difference, depending on the conditions. Generally, the principal factors influencing the PEO coating thickness are known to be 
current modes (DC, AC, unipolar pulse, bipolar pulse), composition and concentration of electrolyte as well as PEO process time. In this study, it was revealed that the frequency of pulse could have a significant influence on thickness growth of PEO coating [11]. Other researchers have reported the similar results with respect to relationship between the applied frequency and the thickness growth of PEO coating. They claimed that the increase of applied frequency promotes the thickness growth rate for PEO coating of AZ91D Mg alloy [12]. However, the result of this study is limited to the frequency effects with a relatively low duty cycle, and it is worth noting that different influences of frequencies can be expected at higher duty cycle. Therefore, it is important for pulsed $\mathrm{PEO}$ process of $\mathrm{Al}$ alloys to correlate duty cycle with frequency, and it is more desirable to establish relationship between frequency and duty cycle.



Fig. 6. Polarization curves of PEO coatings and of the substrate in seawater.

Figure 6 exemplifies the potentiodynamic polarization behavior in seawater solution for PEO coatings produced at different applied frequencies and their electrochemical parameters determined by Tafel extrapolation method. The potentiodynamic polarization curve can be obtained by applying a potential sweep to a specimen in aqueous solution, measuring and plotting cell potential against current density. The curve provides useful information on electrochemical corrosion characteristics of the specimen. All PEO coatings represented more noble corrosion potential than the substrate $(-0.799 \mathrm{~V})$, showing a potential difference of approximately $0.1 \mathrm{~V}$. The PEO coating produced at frequency of $100 \mathrm{~Hz}$ has exhibited the most noble corrosion potential $(-0.676 \mathrm{~V})$. Considering the corrosion current density, all PEO coatings had a lower corrosion current density than the substrate $\left(3.5 \times 10^{-7} \mathrm{~A} / \mathrm{cm}^{2}\right)$. In particular, the $\mathrm{PEO}$ coating produced at $100 \mathrm{~Hz}$ had the lowest corrosion current density, which is one order of magnitude lower than that of the substrate, followed by the PEO coating produced at $500 \mathrm{~Hz}\left(1.2 \times 10^{-7} \mathrm{~A} / \mathrm{cm}^{2}\right)$. The PEO coatings produced at $1000 \mathrm{~Hz}$ and $2000 \mathrm{~Hz}$ represented the highest corrosion current density among tested PEO coatings, both showing similar electrochemical behavior. The above result indicates the overall improvement of corrosion resistance by PEO coating as compared to the substrate (non-PEO processed). The different behavior with the applied frequencies might be attributable to the cross-sectional microstructure, rather than elemental composition or surface morphology of the coating layer. The PEO coating at $100 \mathrm{~Hz}$ has shown a rather porous surface structure, while its cross-section structure appeared dense compared with other coatings. It was observed that increasing applied frequency had promoted crater structures on surface but had increased the formation of cross-sectional pores in the coating layer. Such through-thickness type of pores provides a path for ingression of corrosive solution, which can in turn initiate corrosion of substrate. The porosity in PEO coatings is formed by physical entrapment of oxygen evolved during $\mathrm{PEO}$ process within the coating layer [13]. Although it is quite challenging to prevent porosity formation during $\mathrm{PEO}$ process, the optimization of process parameters may help to suppress the porosity to a certain degree.

\section{Conclusions}

In this paper, we investigate the influence of applied frequency on the microstructural and electrochemical characteristics during pulsed PEO coating process of $\mathrm{Al}-\mathrm{Mg}$ alloy, and the following conclusions have been reached:

1. In pulsed PEO coating of Al-Mg alloy, all frequency conditions exhibited a similar dielectric breakdown voltage with a slight difference in micro-discharge behavior, an especially high intensity observed at a relatively low frequency.

2. Controlling the applied frequency did not produce a large difference in elemental composition and crystalline phases of the surface layer, while the frequency had a pronounced influence on the surface and cross-sectional microstructure. Both thickness and surface roughness have shown an increasing tendency with the increase of the applied frequency.

3. Regardless of applied frequency, the pulsed PEO coating process resulted in an improvement of the corrosion resistance of Al-Mg alloy. Particularly, the applied frequency of $100 \mathrm{~Hz}$ resulted in the most noble corrosion potential and one order of magnitude lower corrosion current density than that of the substrate.

\section{Acknowledgments}

This research was a part of the project entitled "Construction of eco-friendly $\mathrm{Al}$ ship with painting, and maintenance/repairment free", funded by the Ministry of Oceans and Fisheries, Korea. 


\section{References}

[1] R.H.U. Khan, A.L. Yerokhin, T. Pilkington, A. Leyland, A. Matthews, Surf. Coat. Technol. 200, 1580 (2005).

[2] E.V. Parfenov, A.L. Yerokhin, A. Matthews, Surf. Coat. Technol. 201, 8661 (2007).

[3] R.O. Hussein, D.O. Northwood, X. Nie, J. Vac. Sci. Technol. A 28, 766 (2010).

[4] A.L. Yerokhin, X. Nie, A. Leyland, A. Matthews, S. Dowey, Surf. Coat. Technol. 122, 73 (1999).

[5] V. Dehnavi, B.L. Luan, D.W. Shoesmith, X.Y. Liu, S. Rohani, Surf. Coat. Technol. 226, 100 (2013).

[6] G. Sundararajan, L.R. Krishna, Surf. Coat. Technol. 167, 269 (2003).
[7] P.S. Santos, H.S. Santos, S. Toledo, Mat. Res. 3, 104 (2000).

[8] R. Hussein, D.O. Northwood, X. Nie, Mat. Sci. Applic. 5, 124 (2014).

[9] Z. Yao, Y. Jiang, Z. Jiang, F. Wang, J. Mater. Sci. 42, 9434 (2007).

[10] R.C. Barik, J.A. Wharton, R.J.K. Wood, K.R. Stokes, R.L. Jones, Surf. Coat. Technol. 199, 158 (2005).

[11] A.D. Pogrebnyak, A.S. Kaverina, M.K. Kylyshkanov, Prot. Met. Phys. Chem. Surf. 50, 72 (2014).

[12] Y. Yang, H. Wu, J. Mater. Sci. Technol. 26, 865 (2010).

[13] E. Matykina, A. Berkani, P. Skeldon, G.E. Thompson, Electrochim. Acta 53, 1987 (2007). 